\title{
PRÁTICAS SUSTENTÁVEIS NAS PRODUÇÕES DO POLO JOALHEIRO DO PARÁ
}

Jorge José Pereira Duarte

Universidade Federal do Pará

djorgeduarte@hotmail.com

Resumo: O presente artigo traz uma análise desenvolvida no Polo Joalheiro do Pará no intuito de descrever as formas que a sustentabilidade é aplicada nos processos de concepção das joias, tomando como referência o local da pesquisa. É estabelecido o contexto de mercado em que a joia se apresenta na contemporaneidade e seu papel em frente ao surgimento recente de outros segmentos do setor de acessórios de moda. Através da prática do design com consciência ambiental é identificado como tais ações podem contribuir e beneficiar os produtores, e quais as mudanças significativas são encontradas na várias etapas do ciclo de vida dos produtos.

Palavras chave: joias, sustentabilidade, design.

Abstract:This article provides an analysis developed in the Polo Jeweler of Pará in order to describe the ways that sustainability is applied in the jewelry design processes, taking as reference the locus of the research. The market context in which the jewelry is presented in contemporary society is established and its role in front of the recent emergence of other segments of the fashion accessories industry. Through design practice with environmental awareness is identified how such actions can contribute benefits to the producers, and what significant changes are found in various stages of product life cycle

Keyowrds: jewel, sustentability, design 


\section{INTRODUÇÃO}

Muito tem se falado nos últimos anos sobre a conscientização e prática de ações cotidianas que podem trazer o mínimo de impactos negativos ao meio ambiente. Pensar em caminhos que viabilizem esses processos é uma das premissas do contexto sustentável, que vem se disseminando em muitas áreas de atividades, produção e consumo.

Um dos setores que está em processo de adequação a esses ideais é a moda, segmento de mercado que nas últimas décadas teve um crescimento meteórico não apenas economicamente, como também em volume da atividade produtiva. Ao trazer este contexto como forma de reflexão, levantam-se algumas questões relacionadas as etapas que constituem o ciclo de vida desses incontáveis produtos lançados no mercado diariamente, desde a obtenção de suas matérias primas até sua forma de descarte.

Utilizando o setor de acessórios de moda como ponto principal desta discussão, são apresentadas as práticas sustentáveis utilizadas pelos produtores do Polo Joalheiro do Pará e como elas podem trazer benefícios para essas empresas. A partir deste ponto de vista, são apresentados processos que pertencem a várias etapas do sistema de concepção das joias desenvolvidas para comercialização no referente local e sua contribuição para a reafirmação de um dos principais objetivos da Escola de Joalheria do Pará.

\section{DESENVOLVIMENTO}

Quando é posto em discussão a questão da sustentabilidade, uma das primeiras coisas a se considerar é que todas as etapas do processo contribuem para a consciência ecológica do produto, da obtenção de suas matérias constituintes até seu manuseio, manutenção e descarte pelo consumidor. "Quando falamos de sustentabilidade ambiental relacionada ao desenvolvimento de produtos, nos referimos aos critérios, aos métodos e aos investimentos do Life Cycle Design (LCD). O projeto, assim, faz parte do ciclo de vida dos produtos." (VEZOLLI, 2008, p. 197). Ter essa visão macro do projeto contribui inclusive para a boa relação que o consumidor pode criar com sua experiência de compra, além de agregar à imagem da empresa a consciência na definição de seus processos em consequência com os possíveis impactos ao meio ambiente, considerado este um bom diferencial para as exigências do mercado atual.

O agente principal desse valor agregado ligado às praticas sustentáveis se dá pelo estado de conscientização que se passou a ter sobre as fontes naturais de insumos. "A percepção dos limites ambientais também tem provocado mudanças no modelo de produção industrial e nas formas de consumo" (KRUCKEN, 2009, p. 57). Por conta disso, uma grande parcela da população que participa ativamente no mercado busca conhecer um pouco além do que é exposto nas vitrines, ter consciência da procedência do produto e sob que parâmetros projetuais o mesmo foi concebido.

Tendo como referência os dados acima descritos, nota-se que além da pesquisa conceitual, criação e detalhamento técnico, é competência do designer buscar soluções para diversos outros problemas que fazem parte do sistema de produção de forma geral. Quais materiais utilizar para manter a boa durabilidade, reduzir custos e extinguir ao máximo a geração de resíduos? Quais processos podem agilizar a produção e ao mesmo tempo assegurar a qualidade? Quais etapas do processo 
produtivo podem ser subvertidos em qualidades a serem utilizadas como atrativo conceitual para o consumidor?

Muitas dessas respostas podem ser conseguidas ao analisar o produto e suas etapas produtivas, no objetivo de identificar problemas contidos nas mesmas. É necessário a imersão dos profissionais responsáveis pelo projeto em vários setores que formam a cadeia produtiva. Unindo sua experiência prática ao domínio teórico, o processo de otimização das necessidades projetuais pode resultar em inovações que farão deste um destaque em relação aos concorrentes de seu nicho de mercado. "A importância de uma aproximação ao instrumento de análise é a de individualizar e verificar as vantagens ambientais, juntamente com as econômicas e competitivas, para o mercado e, assim, intervir com uma visão sistêmica, individualizando todas as oportunidades de ecoeficiência" (VEZOLLI, 2008, p. 199). As vantagens são significativas, como reduções do custo de produção, valorização do produto com aumento de seu preço final, ou mesmo a redução de processos consequentes do processo, como direcionamento de resíduos não aproveitados.

No caso do Polo Joalheiro do Pará, a prática sustentável é destacada como uma das bases de seus objetivos desde sua criação. "A qualidade artesanal das produções da Escola de Joalheria do Pará deverá consolidar também um exemplo de cultura produtiva eco-compatível e ecossustentável, alinhada com as renovadas exigências globais de respeito à vida no planeta" (FRANCHI, 2011, p.33). Como consequência disto, profissionais do setor joalheiro, em sua maioria ourives e artesãos, buscaram formas de atingir tais objetivos. Com as medidas de incentivo do programa, as joias paraenses passam a ser conhecidas por sua criatividade estética e conceitual, mas também pelas muitas formas de desenvolver produtos com respeito à natureza.

É no sentido de buscar respostas sobre a adequação destas exigências que se toma a propriedade de fala baseada na experiência prática de participação constante no referente programa. Conhecendo a complexidade dos diversos setores desse lugar, que também é conhecido como Espaço São José Liberto, é percebida a importância de se realizar uma análise de forma setorial para identificar as iniciativas que tornam a fabricação e comercialização de joias no Polo Joalheiro do Pará um sistema sustentável em várias áreas de seus fazeres produtivos.

\subsection{Reutilização e Manutenção de peças}

Ao se analisar o setor de acessórios, o qual a joia está inserida, percebe-se a quantidade massiva de joias de imitação em relação as joias genuínas. Tratam-se de réplicas feitas com materiais de menor valor e com menor custo de produção, por sua fabricação em larga escala, e que apresentam características diferentes de suas similares originárias.

O crescimento meteórico da joia de imitação, entretanto, só ocorreu mesmo depois de 1981, após o grande abismo criado, na década de 1970, entre a joia preciosa e a de imitação, então considerada [...] um substituto barato e alegre da joia genuína. E o comércio dos acessórios, no geral, tornou-se mais saudável. A joia de imitação e a bijuteria melhoraram em qualidade, e seus preços subiram vertiginosamente. GOLA, 2013, p.127.

Por mais que o poder de compra aos acessórios se tornou mais acessível devido ao seu preço, muitas coisas podem ser apontadas em contrapartida. A primeira dela é 
sua durabilidade, que difere significativamente em comparação com as joias preciosas, principalmente quando se tratam de peças feitas em metais como latão e com banho ou folheado de outros metais.

Tais peças apresentam vida útil bastante reduzida, fato que dialoga com sua ligação a tendências de mercado também passageiras. Estes fatores contribuem para o aumento do volume de compras, seja para repor peças defeituosas, como para substituir uma tendência de moda por outra. Por muitas vezes se tratarem de peças industriais produzidas através de meios mecanizados, questões como consertos e ajustes se tornam bem difíceis de serem executados, tendo como o descarte no lixo domiciliar um dos seus mais frequentes fins.

Já as joias preciosas, muitas vezes pelo valor e alta durabilidade de seus materiais, podem ser recicladas para a produção de novas peças. "Normalmente nesses casos, o metal será fundido, e as gemas, se houverem, é que determinarão a nova criação" (SALEM, 1998, p.181). No caso da joalheria, muitos de seus materiais são passíveis de manipulação artesanal, técnicas dominadas com excelência pelos ourives do Polo Joalheiro do Pará. A grande maioria das empresas com ponto fixo neste espaço trabalham com a produção de joias de projeto exclusivo, onde a utilização de metais nobres e gemas pertencentes ao consumidor é possível.

O serviço de manutenção (como polimentos e limpezas) e reparos (a exemplo de soldas, trocas de fecho) das peças adquiridas nestas empresas ou mesmo externamente são possíveis, sendo importante destacar a presença de uma oficina de reparos em funcionamento durante todo o horário de funcionamento do Polo. Tais ações de valorização e ressignificação dos materiais dificultam o descarte de materiais de valor como os usados na joalheria, sejam eles gemas, ouro ou prata, aumentando assim o tempo de uso da peça pelo consumidor, ou mesmo transformando esses insumos em produtos novos, iniciando um novo ciclo de vida.

\subsection{Práticas Sustentáveis nos Metais}

Um fator importante a ser levado em consideração em qualquer área de concepção de produtos é que quanto menos resíduos descartados, melhor rendimento financeiro o projeto proporcionará, fator de destaque principalmente na produção peças de joalheria, devido ao valor que seus materiais constituintes possuem.

Desta forma, buscam-se saídas de reaproveitar boa parte dos resíduos gerados durante os processos de manipulação dos metais. "Na fabricação de uma joia, o metal passa pela serragem e limagem. Com decorrer desses processos, vão se acumulando limalhas de metal, que devem ser reaproveitadas, evitando assim o desperdício do metal" (SANTOS, 2013, p. 107-108). O "pó" dos metais e pequenos pedaços resultantes desses processos é comumente chamado pelos ourives de "lixo", termo curiosamente utilizado para resíduos que passam por todo um cuidado em serem captados e armazenados.

A coleta deste material tem a finalidade de sua reutilização, onde após a retirada de outros resíduos de metais ferrosos com o uso de um imã, com um processo similar ao de fundição de liga metálica onde os metais são expostos a uma alta temperatura de um maçarico, é realizada a queima dos materiais orgânicos como restos de lixas, madeiras e papeis que possam estar presentes na limalha. "Após a purificação, os metais são limpos, e está completo o processo de refino. Feito isso, o metal está pronto para ser ligado e trabalhado" (SANTOS, 2013, p. 108). Muito facilmente pode-se conseguir uma grande quantidade de metais apenas 
reaproveitando as limalhas coletadas durante o tempo de trabalho na bancada do ourives. Percebe-se que dessa forma a perda de metal na fabricação de joias é mínima, reduzindo consideravelmente o lançamento de insumos metálicos na natureza.

Além da reutilização de insumos gerados na própria oficina de joalheria, pode ser citada uma prática específica da prata que através de sua execução, fornece para grande parte dos produtores do Polo Joalheiro do Pará este metal utilizado em abundância nas peças comercializadas lá. Trata-se da reciclagem de prata presente nas pranchas de radiografias, utilizadas mundialmente em diversos segmentos da área de saúde.

A falta de um correto gerenciamento de resíduos sólidos, seja por parte da gestão pública ou privada, os resíduos de chapas radiográficas e filmes tem sido destinados incorretamente à lixões a céu aberto ou mesmo aterros sanitários em muitas cidades do Brasil e do mundo podendo atingir os lençóis freáticos e causarem imensos danos a saúde humana e animal. MACHADO, 2014.

Para evitar tais danos, foram desenvolvidas diversas formas de extração de materiais de chapas de radiografia, métodos que possibilitaram o surgimento de pequenos empreendimentos voltados pro setor de reciclagem, usinas voltadas para essas ações específicas. Esta prática se manifesta de forma presente no fornecimento de metais para empresários presentes do Polo Joalheiro do Pará, trazendo mais uma opção de fornecimento de matéria prima, que acima de tudo tem como premissa a prática sustentável de redução de resíduos.

\subsection{Práticas Sustentáveis nas gemas}

No caso das gemas utilizadas na joalheria, o reparo também é possível, através da relapidação de peças com defeito ou que precisem de novos formatos para o uso em algum outro projeto. "Se a pedra contem danos, devido ao tempo de uso, ou se a lapidação pode ser melhorada, são avaliações a serem feitas e decididas com o cliente" (SALEM, 1998, p. 181). Neste caso entra em ação o lapidário, profissional responsável pelo embelezamento dos materiais gemológicos através de seu beneficiamento. A quantidade de jazidas na região é bastante significativa, com ênfase na grande variedade de quartzos.

Embora a cultura de lapidação no Estado do Pará não tenha uma grande representatividade empresarial, há diversos profissionais que trabalham no setor. Entre eles, pode ser citado o diferencial no trabalho da lapidária Leila Salame, proprietária da loja de gemas no Espaço São José Liberto. "Leila Salame tem uma oficina, ministra cursos, fornece gemas para a Loja Una, para muitos produtores do projeto "Joalheiro do Estado" e para ourives, vendedores independentes, artesãos e lojistas da grande Belém e de outras cidades do Estado" (MAIA;MEIRELLES, 2011, p. 107). Além de fornecer matéria prima já beneficiada para várias empresas da região, a mesma desenvolveu sua própria técnica autoral de lapidação, essa denominada "lapidação diferenciada", que consiste na gravação de grafismos indígenas na própria gema.

Sua experiência de mais de 20 anos de trabalho com gemas aguça seu olhar e habilidade no restauro e relapidação de gemas pela sua empresa "Gemas do Mundo", sendo mais um diferencial para as atividades presentes no Polo Joalheiro do Pará.

Assim como na ourivesaria, a lapidação também gera resíduos, neste caso os 
materiais triturados de gemas. Como projeto para a utilização deste insumo, é demonstrado aqui o trabalho de pesquisa e experimentação de diversos profissionais do setor, que consiste na reutilização do pó de pedra como pigmento para a esmaltação denominada "incrustação paraense", exemplificado pela Figura 1, que apresenta um pingente em prata, e uso da técnica com resíduos de coral, argila, casca de ovo, malaquita e turquesa, com design e ourivesaria de Joelson Leão.

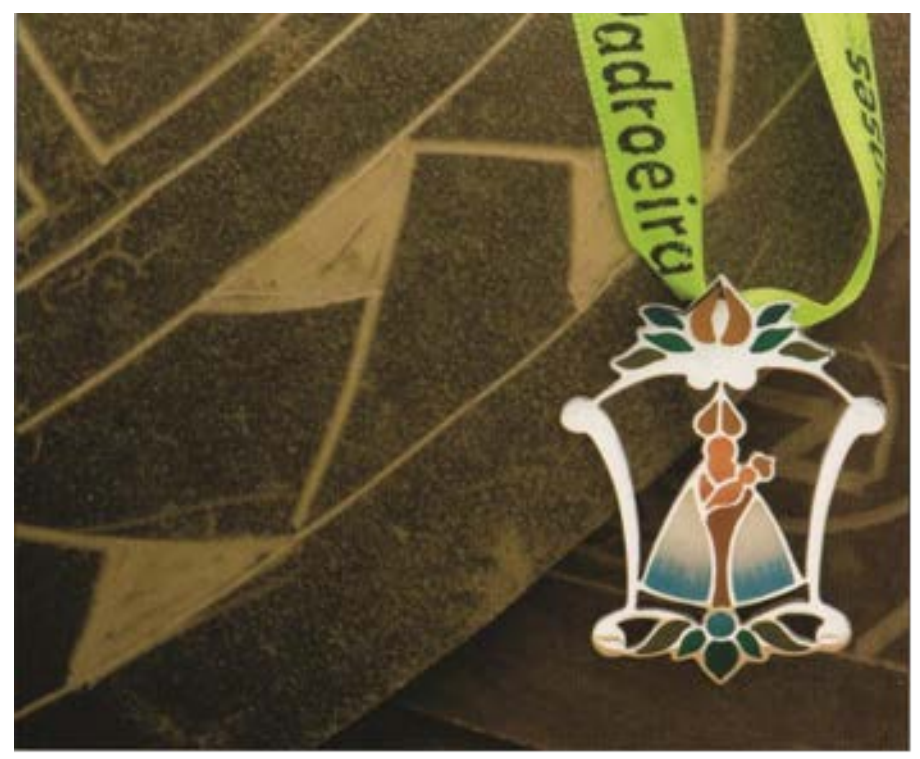

Figura 1 - Pingente "Rainha da Fé na Berlinda", produção da empresa Amajoias. Fonte: Catálogo de Joias de Nazaré: a fé no tempo, 2008.

Inicialmente entitulada como "mosaico de pó de pedra", "foi trazida ao Pará pela instrutora Lídia Hiroku Yugue, ao ministrar um curso de formação de instrutores em 1999, nos primórdios do Polo Joalheiro" (COSTA apud ABRAHIM, 2011, p. 111). Essa técnica foi se desenvolvendo nas experimentações dos ourives presentes no Polo e hoje faz parte de uma grande parte dos projetos, por trazer o colorido de diversos materiais, criando uma estética inovadora para as peças.

\subsection{Práticas Sustentáveis nos Materiais Alternativos}

Não somente nos materiais comuns à joalheria a sustentabilidade pode ser percebida nos trabalhos do Polo Joalheiro do Pará, pois nas inovações que foram transportadas para o universo das joias uma das principais está relacionada aos insumos naturais próprio do lugar. "Os produtos da sociobiodiversidade têm despertado crescente interesse das indústrias e dos consumidores. [...] Estão relacionados com a manutenção e valorização de práticas e saberes das comunidades, e com a qualidade de vida e do ambiente" (KRUCKEN, 2009, p.72-73).

São desses saberes locais que se elenca um papel de extrema importância nesse nicho de produtos. É através dos saberes artesanais desenvolvidos através de suas experiências práticas que surgem grandes oportunidade de inovação projetual. Tal importância é bem clara no Manifesto da Escola de Joalheria do Pará. "O ambiente do home/artesão é aquele cuja natureza deve ser respeitada, que traduz uma técnica pela qual o homem age como protagonista, não se deixando manipular pelo poder tecnológico da era digital" (FRANCHI, 2011, p. 33). Agindo em parceria com o designer na busca de soluções que otimizem o uso dos materiais artesanais, busca-se o melhor 
aproveitamento das técnicas manuais nos projetos de joias, sempre respeitando suas origens e limitações operacionais.

A utilização de materiais locais na construção das joias tem uma origem tão antiga quanto a própria prática de ourivesaria, e na atualidade esses valores têm sido resgatados. "Na joalheria contemporânea, é cada vez mais valorizado o uso de materiais não convencionais" (SANTOS, 2013 p.69). No setor da joia com características regionais, os materiais alternativos podem trazer a estética que conecte a peça com aquele lugar.

Dentre as práticas sustentáveis mais importantes desta categoria presentes no locus da pesquisa, temos o beneficiamento e remanejamento funcional de insumos de origem tanto animal quanto vegetal. No caso dos insumos animais, o mais expressivo segundo a visão desta pesquisa são o osso e o chifre de búfalo. Por conta da cultura de pecuária bubalina na região (principalmente na ilha do Marajó), a carne e o couro são facilmente aproveitados para outras produções, descartando os insumos acima citados. Surge através do trabalho do artesão o beneficiamento e talhe desses materiais para a joalheria, forma de valorizar um insumo antes sem uso algum e que possui, no caso do osso bubalino, beleza semelhante ao do marfim.

No caso dos insumos vegetais, o grande destaque se dá para o ouriço ${ }^{1}$ da castanha-do-pará, as sementes, geralmente usadas como contas, mas por vezes tingidas, como no caso da semente de açaí ou mesmo através de seu talhe, como na jarina. Nas produções com madeiras e caules, por serem usadas em pedaços bem menores do que em outras áreas, a exemplo do setor de móveis e design de interiores, geralmente são utilizados resíduos já dessas atividades, trazendo o conceito do reaproveitamento bem presente na produção de joias.

A grande diversidade de madeiras na região permite com que tenha-se uma grande variedade de cores, propiciando técnicas como a marchetaria ${ }^{2}$, em mostrar essa diversidade em uma mesma peça. Na figura 2 a diversidade de materiais pode ser percebida nos conjuntos "tradição do corpo" e "ponta de flecha", desenvolvidos para a empresa HSCriações \& Design.

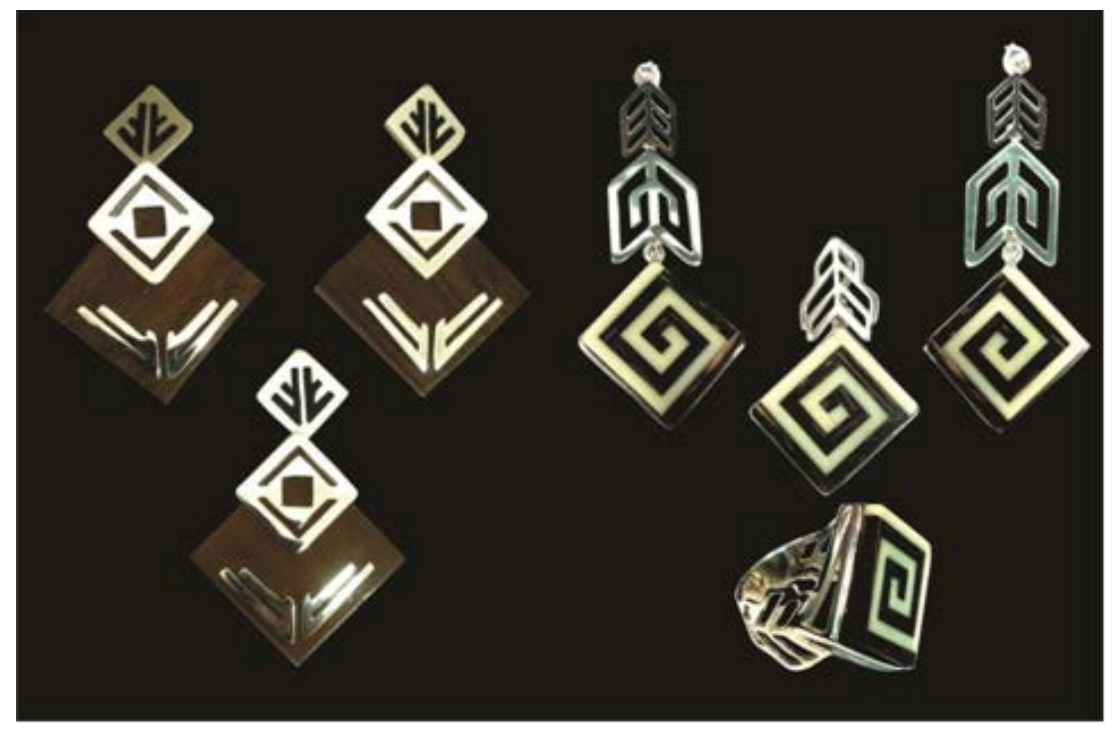

Figura 2 - Conjuntos "Tradição do Corpo" e "Ponta de Flecha". Fonte: elaborado pelo autor, 2014.

\footnotetext{
1 Espécie de coco que guarda o fruto da castanha-do-pará

2 Formação de imagens através do encaixe de materiais de colorações diferentes
} 
No primeiro caso se encontra a prata com a madeira de muiracatiara e no segundo conjunto há a combinação da prata com a técnica de marchetaria, utilizando o osso de búfalo (detalhes brancos) e o caule de pupunheira (detalhes escuros). Percebe-se aí um pequeno exemplo do contraste gerado pela variedade estética que se pode atingir inserindo os materiais locais e em suas misturas, a presença de uma estética cada vez mais exótica, sempre mantendo os padrões de qualidade exigidos pelo mercado de joias.

Um caso importante em frisar é que além da venda de joias, o Polo Joalheiro do Pará possui seu setor de artesanato, com uma sessão direcionada para acessórios de moda. Desta forma, os mesmos artesãos que produzem e beneficiam esses materiais naturais para o uso na joalheria também desenvolvem sua produção própria no segmento de acessórios. Além de reforçar o sentido de liberdade criativa e desprendimento empregatício com alguma empresa, há a possibilidade do artesão gerir independentemente em seu segmento próprio, transformando-se no autor principal de sua produção. Aponta-se aí benefício importante de conseguir atender não somente o setor de consumo joias, mas também o de peças de valores mais baixos, mantendo em ambos os casos tanto a qualidade como a consciência sustentável.

\section{CONCLUSÃO}

O fato do programa de incentivo a indústria joalheira no Estado do Pará ter surgido na contemporaneidade contribuiu para que desde a sua fundação questões atuais como a preocupação com o meio ambiente e a valorização dos profissionais da cadeia produtiva como um todo estejam presentes. Através do levantamento que foi realizado neste programa, percebe-se que a sustentabilidade está presente em muitas de suas práticas, seja no apoio à manutenção e reparos de peças, seja nos processos produtivos com o uso de metais, gemas e materiais alternativos.

Como principais benefícios que tais práticas propiciam, aponta-se o resgate de materiais descartados de forma indevida no meio ambiente, a reutilização de insumos gerados durante a produção de peças, a possibilidade de aumento de vida útil através da manutenção e reparos e o criação de um novo ciclo de vida para produtos com algum defeito ou que se apresentem fora das tendências de mercado. Muitas dessas práticas apontadas refletem diretamente tanto na redução de custos de produção para o empresário, como por vezes na redução de valor final para o cliente, fatores primordiais para potencializar a competitividade de um produto em seu nicho de consumo.

Algumas das práticas, como o reaproveitamento de prata de radiografias não são de exclusividade do Polo Joalheiro do Pará, mas que por se enquadrar com a proposta de prática sustentável, têm sido executados com excelência por profissionais do setor e facilmente aceitos pelos produtores de joias. Em contrapartida, técnicas como a incrustação paraense, aperfeiçoada pelos profissionais que compõe o programa, trazem um diferencial estético que dialoga harmoniosamente com os processos criativos utilizados na concepção de produtos comercializados no Espaço São José Liberto. Neste mesmo ponto de vista, os materiais locais beneficiados pelos artesãos também contribuem de forma significativa para a criação de uma estética local da joia paraense, trazendo unicidade para seus objetos representativos. 
A criação da estética local através das inspirações nos elementos do lugar, unida ao grau de boa qualidade de produção e acabamento e com a atribuição do conceito de prática sustentável, fazem das joias paraenses um produto de grande potencial não somente no setor joalheiro nacional, como também a nível global.

\section{REFERÊNCIAS}

Associação Brasileira de Normas Técnicas. NBR 6021: Apresentação de periódicos. Rio de Janeiro, 1994.

COSTA, Socorro. Incrustação Paraense: Inovação e Aproveitamento da Gema Orgânica na Joalheria Artesanal In: MEIRELLES, Anna. C. R.; NEVES, Rosa. H. N.; QUINTELA, Rosângela S.; PINTO, Rosângela G.; organizadoras. Joias do Pará: design, experimentações e inovação tecnológica nos modos de fazer. Belém: Paka-Tatu, 2011. p. 111-113.

FRANCHI, Cláudio. Manifesto da Escola de Joalheria do Pará. In: MEIRELLES, Anna. C. R.; NEVES, Rosa. H. N.; QUINTELA, Rosângela S.; PINTO, Rosângela G.; organizadoras. Joias do Pará: design, experimentações e inovação tecnológica nos modos de fazer. Belém: Paka-Tatu, 2011. p. 31-34.

GOLA, E. A joia: história e design. 2. ed. São Paulo: Editora Senac São Paulo, 2013.

KRUCKEN, Lia. Design e território: valorização de identidades e produtos locais. São Paulo: Studio Nobel, 2009.

MAIA, Raimunda F. S.; MEIRELLES, Anna C. R. A arte, o encanto e a trajetória de uma lapidária In: MEIRELLES, Anna. C. R.; NEVES, Rosa. H. N.; QUINTELA, Rosângela S.; PINTO, Rosângela G.; organizadoras. Joias do Pará: design, experimentações e inovação tecnológica nos modos de fazer. Belém: Paka-Tatu, 2011. p. 107-110.

MACHADO, Gleysson B. Usina de Extração de Prata de Radiografia e Filmes

Fotográficos. Disponível em:

$<$ http://www.portalresiduossolidos.com/usina-de-extracao-de-prata-de-radiografias-efilmes-fotograficos/\#more-3812>. Acesso em 04 de fevereiro de 2016.

SALEM, Carlos. Joias: criação e design. São Paulo: 2000joias, 1998.

SANTOS. Rita. Joias: fundamentos, processos e técnicas. Rio de Janeiro: Editora Senac São Paulo, 2013.

VEZZOLI, Carlo. CASTILLO, Kathia (Trad.) Cenário do design para uma moda sustentável. In: PIRES, Dorotéia B.; organizadora. Design de Moda: olhares diversos. Barueri: Estação das Letras e Cores Editora, 2008. p. 197-206. 